\title{
Impact assessment of long-term chronic radiation exposure on plant populations
}

\author{
S. Geras'kin, A. Oudalova, N. Dikareva, V. Dikarev, J. Prytkova, \\ E. Chernonog and T. Novikova
}

Russian Institute of Agricultural Radiology and Agroecology, 249020 Obninsk, Russia

\begin{abstract}
Studies that examine biological effects on non-human biota in natural settings provide a unique opportunity for obtaining information about the potential biological hazard associated with radioactive contamination. The results of long-term field study in the Bryansk Region, Russia, affected by the Chernobyl accident are discussed. Plant populations growing in areas with relatively low levels of pollution are characterized by the increased level of both cytogenetic alterations and genetic diversity. In particular, radioactive contamination of the plants' environment activates genetic mechanisms, changing a population's resistance to exposure. However, there are radioecological situations where enhanced radioresistance has not evolved or has not persisted. A development of a system for protection of the environment from ionizing radiation should be based on a clear understanding of these effects and their contribution to response of populations.
\end{abstract}

\section{INTRODUCTION}

Studies to examine biological effects on non-human biota in natural settings provide a unique opportunity for obtaining information about the potential biological hazard associated with radioactive contamination. To properly understand the effect of normal, real-world contaminant exposures, one must consider actual field conditions. However, for most wildlife groups and endpoints studies that link accumulation, chronic exposure and biological effects in natural settings are scarce [1]. These data gaps imply that the protection of the environment from ionizing radiation will require more experimental data related to effects of chronic low-level exposure to radionuclides at the population level. Therefore, a well-directed accumulation of knowledge is needed and appropriate experimental data analysis is necessary. Previously completed and ongoing field studies that have been carried out in Laboratory of Plant Ecotoxicology, RIARAE with different species of wild and agricultural plants are presented in [2-7]. A wide range of radioecological situations and climatic zones have been covered in frames of this work. To illustrate the main findings, the results of long-term field study in the Bryansk Region, Russia, affected by the Chernobyl accident are discussed here in more details.

\section{MATERIALS AND METHODS}

To study biological effects in chronically exposed Scots pine (Pinus sylvestris L.) populations six test sites were chosen in the Bryansk Region of Russia radioactively contaminated as a result of the Chernobyl accident. Pine cones were collected in winters of 2003-2009. Activity concentrations of radionuclides in soil samples were measured, and doses to the pine trees' generative organs were calculated. Aberrant cells were scored in root meristem of germinated seeds in ana-telophases of the first mitoses. The method of isozymic analysis of megagametophytes was used for an estimation of genetic variability in Scots pine populations. Five enzymatic loci (GDH, LAP, MDH, DIA, and 6-PGD) were studied in endosperms of the seeds collected in 2005. Detailed description of materials and methods used can be found in $[5,6]$. 


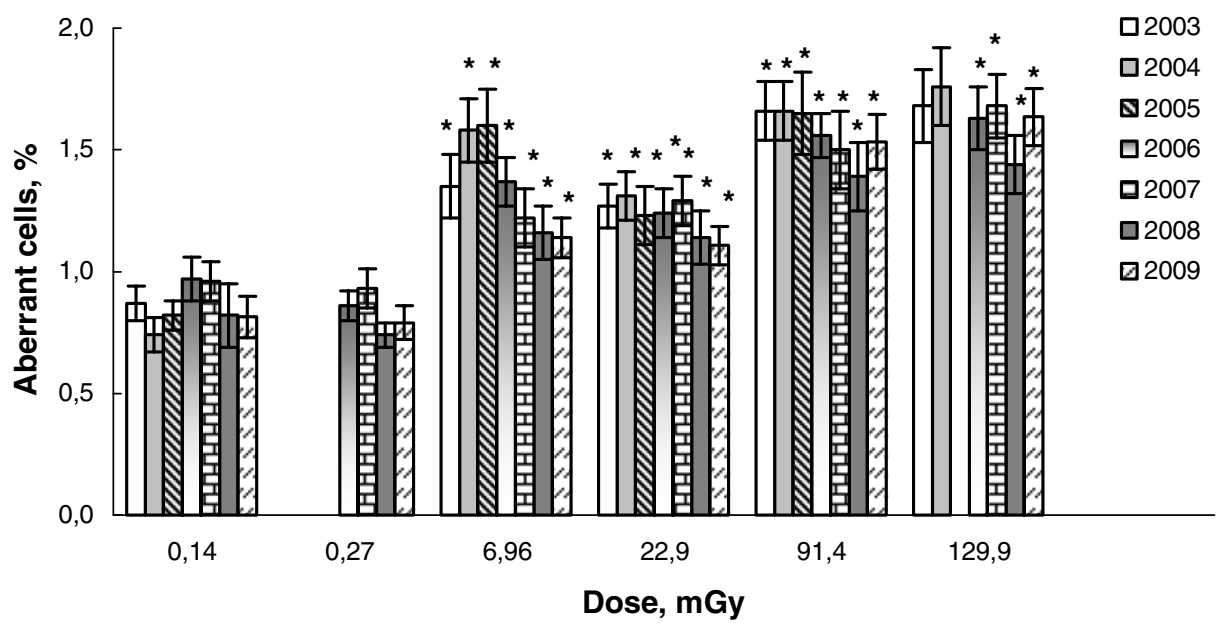

Figure 1. Aberrant cells in root meristem of germinated seeds (\%) from Scots pine populations collected in the Bryansk Region of Russia, 2003-2009. Significant difference from the reference populations: $*-p<0.01$.

\section{RESULTS}

Considerable efforts have been spent searching for biomarkers of effects that might provide risk managers an early warning of pending damage. Documentation of cytogenetic effects holds such promise that the ICRP has recommended it as an endpoint in determining population level impacts to non-human biota exposed to radiation [8]. It was hypothesized that cytogenetic abnormalities caused cell death in gametes and subsequent decrease in reproductive potential. Few studies, however, have actually linked cytogenetic damage to other endpoints known to have a direct impact on population levels, such as mortality, reproductive output or changes in genetic make-up of populations.

The Chernobyl accident caused the dramatic and long-term increase in ambient radiation doses to many forest environments. Sites still exist in the Bryansk Region of Russia, 25 years after the Chernobyl accident, where radioactive contamination significantly exceeds background. In the study reported herein, cytogenetic effects in Scots pine populations growing in the Bryansk Region have been investigated for 7 years, and the findings are presented in Fig. 1. Aberrant cell frequency in root meristem of germinated seeds collected from these populations significantly exceeds the reference level and shows correlation with the dose absorbed. Compiled with data from other our studies [2-4, 7], these findings indicate that an increased level of cytogenetic disturbances is a typical phenomenon for plant populations growing in areas with relatively low levels of pollution.

The annual doses in generative organs of pine trees are about thirty times lower than the $0.4 \mathrm{mGy} / \mathrm{h}$ guideline proposed by IAEA as safe for terrestrial plants [9]. On the other hand, dose rate for two most contaminated sites exceeded the ERICA generic screening value of $10 \mu \mathrm{Gy} / \mathrm{h}$ [1]. These comparisons suggest that radiation levels at the study sites were high enough to induce cytogenetic rather than morphologic abnormalities in the exposed populations. Indeed, the aberrant cell frequency, as well as the occurrence of severe types of cytogenetic alterations in root meristem of germinated seeds collected from the impacted populations, exceeded the reference level during all years of the study [6].

It is becoming increasingly clear that cytogenetic alterations detected in our studies might only be tip of an iceberg, reflecting global structural and functional rearrangements induced in exposed populations. An increase in mutation rate can affect the population genetic structure by producing new alleles or genotypes, and thereby has ecologically relevant effect. Alterations in the genetic makeup of populations are of primary concern since somatic changes, even if they lead to a loss of some individuals, will not be critical in populations with a large reproductive surplus. To analyze whether an 


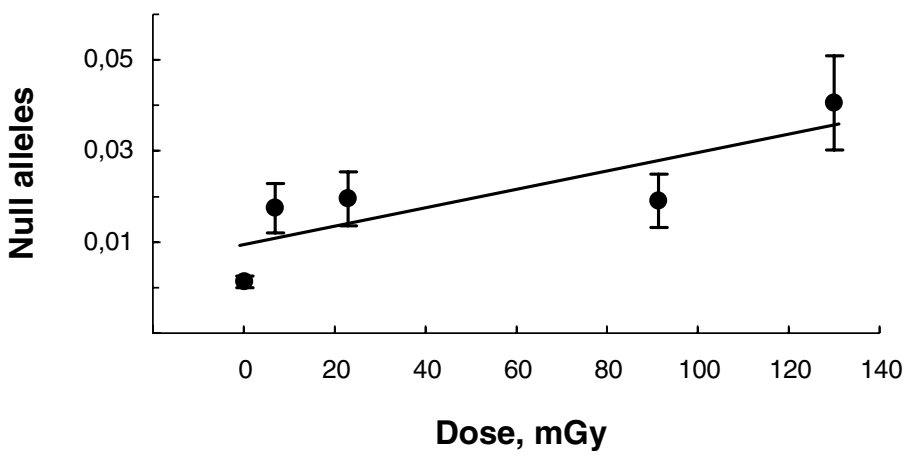

Figure 2. Frequency of null alleles in enzymatic loci of endosperms in dependence on annual dose absorbed by reproductive organs of pine trees, 2005.

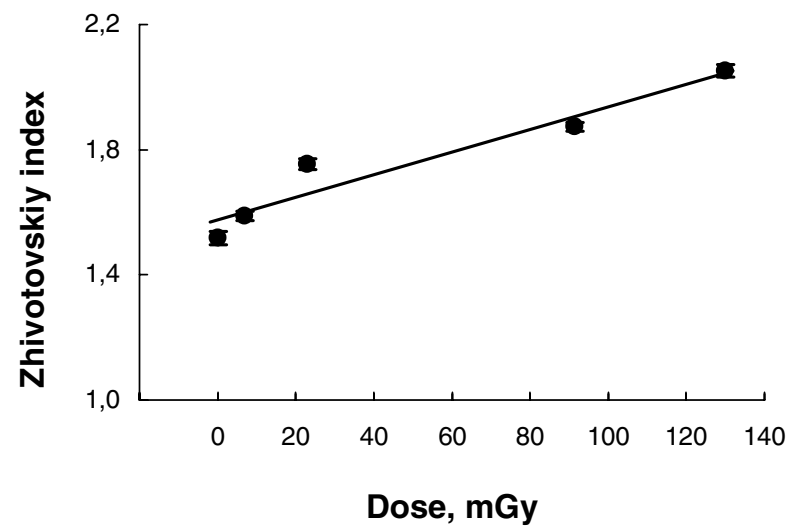

Figure 3. Phenotypic variability estimated via the Zhivotovsky index in dependence on annual dose absorbed by reproductive organs of pine trees, 2005.

exposure to radionuclides causes changes in population genetic structure, we evaluated [5] frequencies of three different types of mutations (null allele, duplication and changing in electrophoretic mobility) of enzymatic loci in endosperm and embryos of pine trees from the studied populations. It is found that chronic radiation exposure results in the significant increase of total occurrence of enzymatic loci mutations. In particular, frequencies of mutations for loss of enzymatic activity increase with the dose absorbed by reproductive organs of pine trees (Fig. 2).

There are plenty of theoretical interpretations of evolution, but what is important is to see what happens in practice. Mutations in plants or animals are not necessary bad events when they do not adversely affect the population fitness. Mutation is one of the mechanisms that maintains genetic variation within a natural population and thus enables that population to cope with an adversely changing environment. Indeed, phenotypic variability in the exposed pine tree populations significantly exceeds the reference level and increases with dose absorbed by reproductive organs of pine trees (Fig. 3).

Populations living under unfavorable conditions (harsh climate, border of the species areal, mancaused pollution) exhibit not only greater polymorphism but also higher heterozygosity than those in optimal conditions. A decrease in heterozygosity within individuals has been associated [10] with decreased resistance to diseases, decreased growth rates and fertility. The observed heterozygosity in pine tree populations at the radioactively contaminated sites is essentially higher then the expected one and increases with dose absorbed by reproductive organs of pine trees (Fig. 4). Keeping in mind all the 


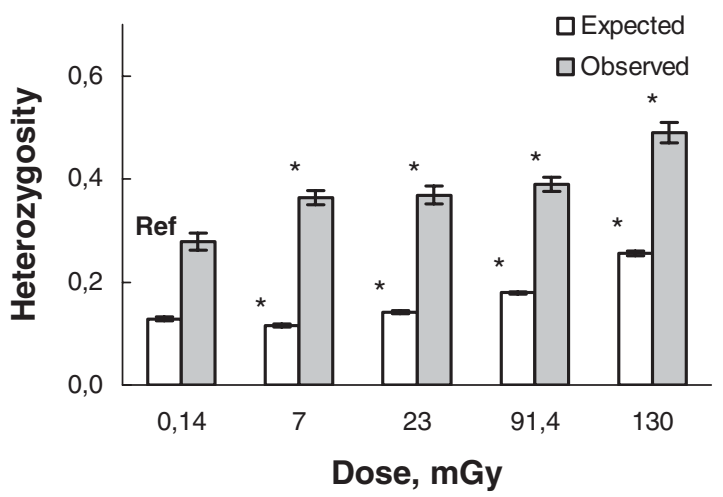

Figure 4. Heterozygosity in endosperms of Scots pines in dependence on annual dose absorbed by reproductive organs of pine trees. Significant difference from the Ref population: $*-\mathrm{p}<0.01$.

data mentioned, it could be concluded that a high level of mutation occurs in the progeny of these pine populations and that their genetic diversity is conditioned by radiation exposure. So, in spite of their low values, dose rates observed can be considered as a factor able to modify genetic structure of populations.

Although great progress has been made in understanding the nature of mutations, too little is yet known about the way in which mutations can lead to observable effects in life traits of organisms and populations. In the first year after the Chernobyl accident a significant decrease in reproductive ability of pines (reduction of seed mass and their number per cone, as well as increase in portion of abortive seeds) was observed at doses over $1 \mathrm{~Gy}[11,12]$. Eleven years after the accident this tendency still persisted. In 1997, the portion of abortive seeds from pine populations that had received doses of 10-20 Gy in 1986 significantly exceeded the correspondent reference level [12]. The effect of radioactive contamination on reproductive ability of pine trees was also observed at the South Urals radioactive trail. Chronic exposure of pine trees at dose rates of 4.2-6.3 $\mu \mathrm{Gy} / \mathrm{h}$ resulted in a significant decline of seed mass, as well as an increase in the fraction of abortive seeds [13]. In 2000-2001, decrease in pollen viability as well as increase the number of anomalous pollen grains in Scots pine populations from the Bryansk region at dose rates of 1.8-5.4 $\mu \mathrm{Gy} / \mathrm{h}$ have been detected [14]. In contrast to the results mentioned above, we failed to find any clear linkage between reproductive ability and doses absorbed by reproductive organs of pine trees (Fig. 5). So, the high mutation rate found in this study (Figs. 1 and 2) had no effect on the reproductive ability of the exposed populations.

An appearance of some standing factors (either of natural origin or man-made) in the plants' environment may activate genetic mechanisms, changing a population resistance to a particular stress. Laboratory studies of repair inhibitions, dose-effect relationships for low- and high-LET radiations, measurements of unscheduled DNA synthesis and an efficacy of the single strand breaks recovery [15] suggest that the divergence of populations in terms of resistance is connected with a selection for changes in the effectiveness of repair systems. Another study on the possible mechanisms of adaptations to radioactive contamination [16] showed extremely low (more than 10-fold) recombination levels, and a higher level of global genome methylation in chronically irradiated plants that may have prevented extensive genome rearrangements. Although our understanding of mechanisms of adaptation is far from complete, these studies give good evidence that the response of biological systems to stress have been produced by normal evolutionary processes in relation to the environments in which the populations occur. This is, of course, a wasteful system since metabolic energy has to be used to produce the adaptive trait even when it is not required. Actually, increased fitness in unfavorable environments is associated [17] with decreased fitness in favorable environments. As a result, there are situations [18] when resistance to environmental changes has not evolved or has not persisted, despite the presence of appropriate genetic variability. Moreover, adaptation is often observed in one species but not found in 


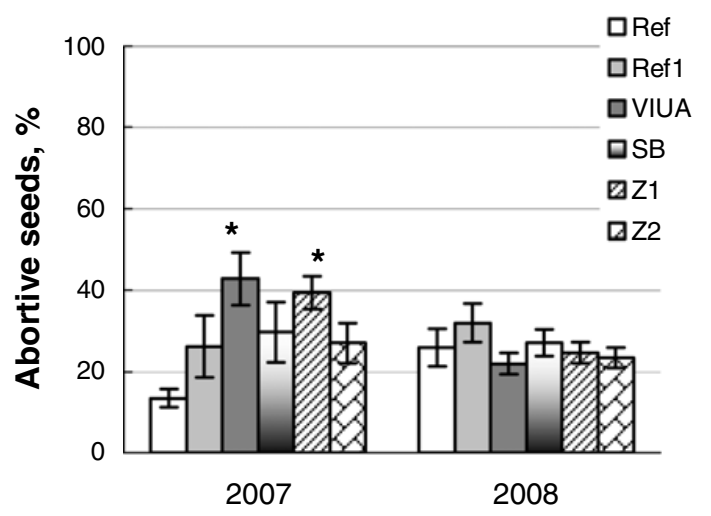

Figure 5. Proportion of abortive seeds in the Scots pine populations at the study sites. Difference from the reference population Ref is significant: ${ }^{*}-\mathrm{p}<0.05$.

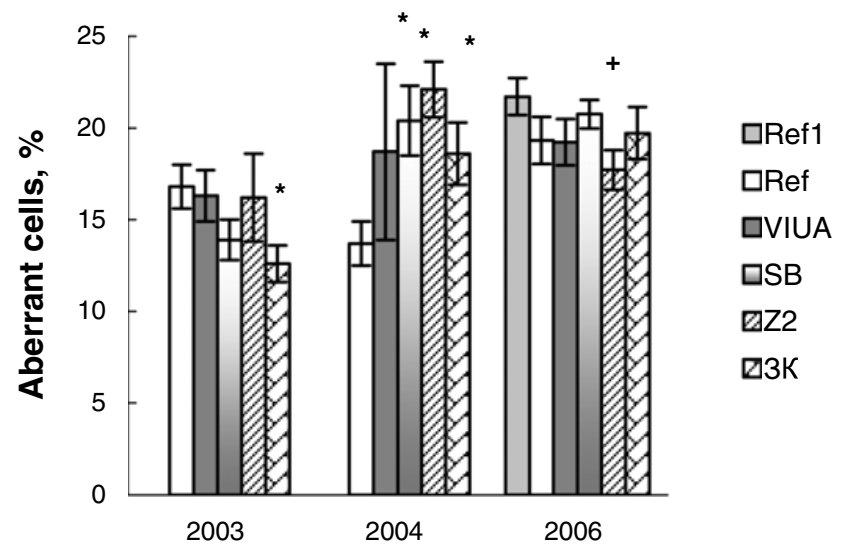

Figure 6. Aberrant cell frequency in root meristems of Scots pine seedlings after acute exposure of seeds to 15 Gy of $\gamma$-rays. * - difference from the Ref site is significant, $\mathrm{p}<0.05 ;+-$ difference from the Ref 1 site is significant, $\mathrm{p}<0.05$.

others, despite an equivalent opportunity and exposure conditions. Indeed, at the South Urals radioactive trace, radioresistance increased 3-4 times in radiosensitive plants, but remain practically unchanged in radioresistant species [15]. It seems that if we examine radio-adaptation in nature, we find as much evidence of it is not occurring, as we do of it is existing. It quickly becomes obvious that the role of microevolutionary processes in a population's response to low-level chronic exposure is still not clearly understood.

The response of a population exposed to low dose rate irradiation depends on both the type of organism and the biophysical properties of radiation. Contrary to the increased radioresistance of seeds from plant populations inhabiting radioactively contaminated territories described in [15], no significant difference in resistance to subsequent $\gamma$-ray exposure between seeds collected from the reference and exposed Scots pine populations was found in our study (Fig. 6). Similarly, the seeds from the crested hairgrass populations that have been experiencing radiation exposure for more than a half century at the Semipalatinsk Test Site and are bearing the elevated levels of cytogenetic abnormalities do not show any reliable increase in resistance to the additional acute $\gamma$-ray exposure [7]. Moreover, the results remain qualitatively the same after the considerable variation in the dose rate of acute irradiation 
(from $2970 \mathrm{~Gy} / \mathrm{h}$ to $39 \mathrm{~Gy} / \mathrm{h}$ ). An improved DNA repair capacity and ability to germinate under abiotic stress was shown in seeds embryos of evening primrose growing near the Chernobyl NPP on sites contaminated with $\gamma$ - and $\beta$-emitters, while on the $\alpha$-, $\beta$ - and $\gamma$-contaminated site such an improvement was not found [19]. This is in line with data on the successful adaptation of wild vetch populations on sites most highly contaminated by $\beta$-emitters, but not by $\alpha$-emitters [20]. Consequently, there are good theoretical and practical reasons for more attention being paid to the mechanisms by which populations become more radioresistant, and to those situations where radio-adaptation appears not to be taking place.

\section{CONCLUSIONS}

Data from large scale field experiments are clearly highly relevant to the development of a new system for radiological protection of the environment. Therefore, an actuality and severity of populationlevel effects within radioactively contaminated areas are among key problems today. The results described here clearly indicate that plant populations growing in areas with relatively low levels of pollution are characterized by the increased level of both cytogenetic alterations and genetic diversity. In particular, radioactive contamination of the plants' environment activates genetic mechanisms, changing a population's resistance to exposure. However, there are radioecological situations where enhanced radioresistance has not evolved or has not persisted. The effects of chronic exposure on living organisms and populations remain poorly explored, and represent a much needed field of research. Much more is to be elucidated in our understanding before we will be able to provide realistic predictions of the biological consequences of chronic, low-level radiation exposures to natural plant and animal populations.

\section{Acknowledgments}

This work was partly supported by ISTC projects No. 3003 and K-1328 as well as Russian Foundation for Basic Research (grants 11-04-00670 and 11-04-97524).

\section{References}

[1] Garnier-Laplace J., Della-Vedova C., Andersson P. et al. J. Radiol. Protect. 30 (2010) 215-233.

[2] Geras'kin S.A., Dikarev V.G., Zyablitskaya Ye.Ya. et al. J. Environ. Radioact. 66(2003) 155-169.

[3] Geras'kin S.A., Zimina L.M., Dikarev V.G. et al. J. Environ. Radioact. 66(2003) 171-180.

[4] Geras'kin S.A., Kim J.K., Oudalova A.A. et al. Mutat. Res. 583 (2005) 55-66.

[5] Geras'kin S.A., Vanina J.C., Dikarev V.G. et al. Biophysics 55 (2010) 324-331.

[6] Geras'kin S.A., Oudalova A.A., Dikareva N.S. et al. Ecotoxicology (2011) DOI 10.1007/s10646011-0664-7

[7] Geras'kin S.A., Mozolin E.M., Dikarev V.G. et al. Radiat. Biol. Radioecol. 49 (2009) 147-157 (in Russian)

[8] ICRP Publication 108. Environmental protection: the concept and use of reference animals and plants. (Pergamon Press, Oxford, 2009).

[9] IAEA. Effects of ionizing radiation on plants and animals at levels implied by current radiation protection standards. Technical Reports Series N.332. (International Atomic Energy Agency, Vienna, 1992)

[10] Theodorakis C.W., Ecotoxicology 10 (2001) 245-256.

[11] Ipatyev V., Bulavik I., Braginsky V. et al. J Environ. Radioact. 42 (1999) 9-38.

[12] Fedotov I.S., Kalchenko V.A., Igonina E.V. and Rubanovich A.V. Radiat. Biol. Radioecol. 46 (2006) 268-278 (in Russian)

[13] Kalchenko V.A. and Spirin D.A. Russ. J Genet. 25 (1989) 1059-1064. 
[14] Scock A.V., Glasoun I.N. and Samoshkin E.N., Forest J 5 (2005) 7-11 (in Russian)

[15] Shevchenko V.A., Pechkurenkov V.L. and Abramov V.I. Radiation genetics of natural populations: genetic consequences of the Kyshtym accident. (Nauka, Moscow, 1992) (in Russian)

[16] Kovalchuk I., Abramov V., Pogribny I. and Kovalchuk O., Plant Physiology 135 (2004) 357-363.

[17] Hickey D.A. and McNeilly T., Evolution 29 (1975) 458-464.

[18] Hoffmann A.A. and Hercus M.J., BioScience 50 (2000) 217-226.

[19] Boubriak I.I., Grodzinsky D.M., Polischuk V.P. et al. Annals Botany 101 (2008) 267-276.

[20] Syomov A.B., Ptitsyna S.N. and Sergeeva S.A. Sci. Total. Environ. 112 (1992) 1-8. 